\title{
O CASTRISMO DE MERCADO: UMA LEITURA LEFORTIANA ${ }^{1}$
}

\author{
Vincent Bloch ${ }^{2}$ \\ Tradução: Pedro Muniz ${ }^{3}$
}

Resumo: $\mathrm{O}$ artigo pretende fazer uma análise do castrismo de mercado, o qual introduziu uma atualização do modelo socialista em Cuba, por meio da perspectiva lefortiana de compreensão do político.

Palavras-chaves: Claude Lefort - Cuba - socialismo - democracia.

\section{Introdução}

Seis anos depois de ter assumido oficialmente as rédeas do poder, Raul Castro decidiu introduzir um processo chamado de "atualização do modelo socialista". Por um lado, a renúncia à ideologia, ao partido único ou ao controle policial permanecem inconcebíveis, e a recusa das divisões sociais permanece no fundamento do regime. Por outro, Raul Castro tentou em certa medida relaxar as restrições que pesaram durante cinquenta anos na liberdade de empreender, de adquirir e de circular. O setor privado, ainda embrionário, testemunha a aceitação de um princípio de realidade: as empresas estatais são incapazes de garantir sozinhas a produção de alimentos, de bens de consumo comuns e de serviços. A eliminação da antiga permissão de saída e, ao mesmo tempo, a implementação da possibilidade acordada à grande maioria dos cubanos de sair da ilha por um período de até dois anos, é uma reforma da mesma espécie. Ao que parece, este é o sentido da "modernização" raulista: dar aos cubanos novos meios de melhorar seu padrão de vida, obter tacitamente em troca a renúncia da reivindicação de seus direitos políticos e, na mesma operação, salvar o país da bancarrota.

Sem o confessar, a "modernização" raulista extrai seus fundamentos da experiência comunista dos últimos vinte e cinco anos através do mundo: a maleabilidade dos modelos chinês e vietnamita é invejável, mas persiste a prudência habitual, e a perda de controle à qual foram submetidos os dirigentes soviéticos serve para realçá-la. O socialismo cubano se

\footnotetext{
${ }^{1}$ Dossiê Claude Lefort: esse texto é parte do dossiê publicado a partir das comunicações realizadas no Colóquio Internacional Claude Lefort: a invenção democrática hoje, realizado na Universidade de São Paulo entre os dias 13 e 16 de outubro de 2015.

2 Pesquisador associado do Centre d'Études Sociologiques et Politiques Raymond Aron da École des Hautes Études en Sciences Sociales (CESPRA/EHESS).

3 Doutorando pela PUC-RIO.
} 
tornou forte com a sua própria experiência: desde que a União Soviética deixou de apoiar a economia da ilha, o regime castrista se perpetuou. E isso apesar da emigração ter se tornado rotina, do jeitinho do povo para encontrar soluções e da corrupção generalizada coisas às quais o regime se viu forçado desde o fim do apoio soviético, e que ainda assim não conduziram à modificação das fortes regras desenvolvidas desde o início dos anos sessenta.

Nesse contexto, dois tipos de análise predominam: o primeiro insiste sobre as múltiplas formas de resistência da sociedade face ao Estado, e o segundo descreve a transição do regime político cubano do totalitarismo para a democracia. No entanto, essas duas abordagens negligenciam a questão do regime político, e é ao retomar as análises de Claude Lefort sobre o regime totalitário que podemos nos questionar em que medida este jogo entre condutas, normas, leis, decisões políticas e ideologia demonstra que o castrismo de mercado escapa da lógica que estava no fundamento da experiência revolucionária cubana.

\section{Alguns mal-entendidos sobre "a dominação totalitária"}

O estudo do período contemporâneo (às vezes chamado de "pós-revolucionário") dá grande ênfase à "subversão" dos objetivos fixados pelo Estado, ou ao "empoderamento" de sujeitos "autônomos", para mostrar que, por trás da continuidade do regime, executam-se processos de negociações informais que debilitam a autoridade do Estado. O questionamento sobre o que permite que o regime político cubano funcione como um todo dá lugar a pesquisas compartimentadas, lidando com grupos definidos $a$ priori ("as mulheres”, “os homossexuais", “os afro-cubanos”, “os novos empresários”, etc.) cujas "contracondutas" e outras formas de emancipação simbólica são interrogadas.

Foi a partir das mesmas premissas que diversos historiadores da Alemanha nazista e da União Soviética já haviam invalidado o conceito de totalitarismo. Ao insistir na existência de conflitos, de disparidades locais, de rivalidades burocráticas e de espaços de autonomia e de resistências, eles recriminaram os teóricos do totalitarismo por terem esquecido de se questionar sobre as noções de historicidade, de período e de duração. Mas os recriminaram também por terem deduzido erroneamente, a partir das intenções dos dirigentes nazistas ou bolchevistas, que as sociedades alemã e soviética haviam sido aniquiladas. Entretanto, mesmo que o ponto de vista que consistia em diferenciar períodos sucessivos no interior dos regimes nazista e soviético tenha imposto sua justeza de outra forma, a maneira em que uma disposição de normas se renovou para além de tal divisão para perpetuar esses regimes a longo prazo recolocou a questão da singularidade dos fenômenos de dominação que eles esconderam. 
Fitzpatrick ${ }^{4}$, por exemplo, evoca o blat (um sistema de relações pessoais que, sob o regime soviético, permitia que as pessoas enfrentassem as penúrias e fixassem acordos) como uma forma de resistência, embora tal sistema entrasse em uma relação simbiótica com a legalidade socialista. Ele era uma norma prática no interior do espaço onde se enredavam a coletivização e a planificação impostas "do alto", e era também o dispositivo regulador pelo qual os indivíduos se orientavam nos labirintos burocráticos. $\mathrm{Na}$ mesma perspectiva, ao invés de separar os tipos de resitenz sem efeito sobre o domínio exercido pelas autoridades nazistas dos tipos cujas formas de alterar o funcionamento do sistema eram possíveis de serem descritas, Orlando Figes ${ }^{5}$ inverteu a perspectiva de Brozsat ${ }^{6}$ : dentro do contexto do período stalinista, ele reflete sobre a maneira em que as práticas e a sobrevivência no cotidiano dos cidadãos "normais" se entrelaçaram com o projeto de dominação totalitária para dar forma à dominação efetiva.

Por outro lado, há cerca de quinze anos a maioria dos "cubanólogos” já descrevem as dinâmicas centrífugas que arruinaram a ordem que eles concebiam até 1989, a saber, a dos "parâmetros do totalitarismo" de Friedrich e Brezinzski ${ }^{7}$. Segundo eles, o conjunto de transformações políticas, sociais, econômicas e culturais que o país conheceu desde então deve ser explicado com a ajuda do conceito de "transição".

Contudo, sendo obrigados a dar conta da diluição do processo que se propuseram a estudar, muitos se perderam nos labirintos da "transitologia", multiplicando as tipologias e variáveis sem nunca conseguir abarcar a totalidade do fenômeno?. Primeiramente, a aptidão das teorias da transição para explicar as mudanças ocorridas dependia, desde o princípio, da capacidade delas de identificar corretamente as regras que faziam com que os regimes fracassados funcionassem. No contexto dos regimes comunistas, essas teorias deixam de lado tanto a questão dos modos de adesão das populações a tais regimes, quanto da incidência das convergências estratégicas de diferentes setores sociais sobre $\mathrm{O}$ funcionamento social deles. Em segundo lugar, os transitológos reduzem as formas de um regime político às transformações da politeia, sem que venhamos a saber se tal termo se reporta ao dispositivo institucional (polity) ou à força da coexistência humana (régime), e sem

\footnotetext{
${ }^{4}$ FITZPATRICK, S.: Everyday Stalinism. Ordinary Life in Extraordinary Times: Soviet Russia in the 1930s, Oxford University Press, 2000.

${ }^{5}$ FIGES, O.: The Whisperers: Private Life in Stalin's Russia, Picador, 2008.

6 BROZSAT, M.: Bayern in der NS-Zeit. Herrschaft und Gesellschaft im Konflikt, Band IV. Teil C, De Gruyter Oldenbourg, 1981

7 FRIEDRICH, C. \& BRZEZINSKI, Z.: Totalitarian Dictatorship and Autocracy, Harvard University Press, 1965.

8 DOMÍNGUEZ, J. I.: “¿Comienza una transición hacia el autoritarismo en Cuba?”, Encuentro de la cultura cubana, 6-7 (otoño-invierno), 1997, pp. 7-23.

9 LINZ, J. \& STEPAN, A: Problems of Democratic Transition and Consolidation, The Johns Hopkins University Press, 1996.
} 
que tenhamos certeza de que os autores diferenciam realmente os dois termos ou que oferecem uma síntese válida.

\section{Lefort e o descarrilamento do projeto totalitário}

A politeia dos Antigos se reportava à constituição, ou seja, à ordem das magistraturas e, ao mesmo tempo, ao modo de coexistência entre os seres humanos. Antes de Montesquieu e antes de Aristóteles, Platão já havia revelado a espessura sociológica e antropológica do conceito de regime político (empregando termos anacrônicos), através tanto da questão da natureza dos materiais tecidos pelo político, quanto do conhecimento que ele possui ${ }^{10}$. A matéria, isto é, os seres humanos, é apenas forjada pelo demiurgo, que não a criou. As condutas dos seres humanos, bem como "as formas de historicidade" nas quais elas se inscrevem, constituem a fortiori o dado a partir do qual o político de Platão não pode fazer nada além de "tecer".

$\mathrm{Na}$ escala societal e tomada a longo prazo, a noção de regime totalitário só pode permanecer válida se ela permitir que seja ressaltado um modo de articulação das partes que formam um sistema, ou um modo de estar em sociedade que determina todas as relações sociais, que derivam de um princípio (no sentido de Montesquieu ${ }^{11}$ ), que procedem de uma lógica (no sentido de Lefort $^{12}$ ) ou que resultam de um fechamento (no sentido de Castoriadis $^{13}$ ). Arendt ${ }^{14}$, Aron ${ }^{15}$ e Lefort, seguindo o espírito de Montesquieu, no fim das contas fizeram do modo de funcionamento dos regimes nazista e soviético uma manifestação da força dos princípios que os fundavam, explicando dessa forma a esterilidade funcional de todas as formas de resistência que viram a luz em seu seio.

Claude Lefort aprofunda em particular o debate sobre as forças do comunismo ao mostrar que as dinâmicas de funcionamento e as percepções do real que garantem a perpetuação da ordem soviética são consubstanciais a uma lei fundadora do espaço social ${ }^{16}$. A esse respeito, ele foi bem mais um pensador do regime totalitário que um pensador do totalitarismo ${ }^{17}$.

${ }^{10}$ CASTORIADIS, C.: Sur le Politique de Platon, Seuil, 1999.

${ }^{11}$ MONTESQUIEU: De l'Esprit des lois, éditions Garnier Frères, 1961 [1748].

${ }^{12}$ LEFORT, C.: “Permanence du théologique-politique ?”, in: Essais sur le politique, Seuil, pp. 251-300.

${ }^{13}$ CASTORIADIS, C.: L'institution imaginaire de la société, Seuil, 1975.

${ }^{14}$ ARENDT, H.: Les origines du totalitarisme \& Eichmann à Jérusalem, Quarto Gallimard, 2002.

${ }^{15}$ ARON, R.: Démocratie et totalitarisme, Gallimard, 1965.

${ }^{16}$ LEFORT, C.: Un homme en trop, Seuil, 1986, p. 48; La complication, retour sur le communisme, Fayard, 1999, pp. 211-222).

${ }^{17}$ LEFORT, C.: "Le concept de totalitarisme", in: Le temps présent, Ecrits 1945-2005, Belin, 2007 [1996], pp. 869-891. 
O interesse de Lefort pela gênese histórica do totalitarismo se encontra na maneira em que ele mostra que o comunismo é uma condensação (no sentido psicanalítico) de processos econômicos e técnicos, de esquemas de ação e de pensamentos heterogêneos aos quais este último deu uma única saída ${ }^{18}$. Lefort faz do fenômeno totalitário não um resultado possível da experiência democrática, mas uma recusa das divisões que ela instaura e uma reversão simbólica da constituição do social que a fundamenta.

Assim, a noção de intenção em Lefort se reporta em primeiro lugar a um conteúdo latente, ao projeto político que dava fim à indeterminação democrática, no contexto e no momento histórico no qual aparecem as condições de sua realização.

Em segundo lugar, Lefort insiste no fato de que o comunismo acomoda também uma intenção específica, uma atração pelo modelo que oferece a possibilidade de formar um partido-Estado, uma nova elite e uma burocracia fornecendo uma base para o regime. Ele insiste que a partir daí o comunismo deu lugar a uma construção do real de um partido movido pela "conquista do Um", estabelecendo um fechamento da História e encerrando o social sobre si mesmo, ao incorporar a lei, o poder, o saber e a ideologia.

A produção do "Um" pela supressão do "Outro" e a inclusão dos coletivos são completados pela definição de um sistema de obrigações recíprocas no âmbito de funções burocráticas, para terminar de cercar a sociedade no interior de uma "barreira"19. É também nesta perspectiva que Lefort propõe um esclarecimento "total" sobre o totalitarismo. Para tal, atuando como um filósofo, ele mostra as ligações que existem entre a natureza do regime político e os princípios de ação que o subjazem; e atuando como um sociólogo, ele mostra a forma como se imbricam um funcionamento social e motivos de ação com categorias singulares do político. Lefort define assim um regime político cujo princípio é de certa forma "a captura", no sentido de que ela é o princípio e ao mesmo tempo o resultado inultrapassável de um funcionamento social que remove o "sentido do possível".

Mas Lefort, cuja abordagem apesar de tudo não é a de um sociólogo, abre ainda mais que Arendt e Aron o caminho que leva a um questionamento sobre a maneira com a qual, paradoxalmente, o "descarrilamento do projeto totalitário" permanece um efeito do fenômeno de "captura" e contribui para a manutenção da "barreira". Em outros termos, tal "descarrilamento" não impede a proeminência de uma "lógica política". Com efeito, Lefort descobre um espaço para a análise das condutas e das normas que elas criam em diferentes níveis do espaço social. Já em Un homme en trop, ele evocava "uma massa considerável de agentes cuja autoridade deve se arranjar com as resistências do 'real', ou seja, apropriar-se dos recursos materiais de fato disponíveis e levar em conta as necessidades e exigências

18 LEFORT, C.: La complication, retour sur le communisme, Fayard, 1999.
19 Ibid, p. 184-185. 
primárias dos homens" ${ }^{20}$. Como Aron, ele mostra como a lógica burocrática tende a frustrar o dinamismo revolucionário.

Lefort não analisa detalhadamente (no nível dos indivíduos e dos grupos) as condutas, os comportamentos ou as estratégias que são testemunhas de uma malversação dos dispositivos legais e institucionais, ou de uma inadequação dos motivos de apoio a esses dispositivos com relação às expectativas das autoridades. Todavia, ele se questiona sobre qual plano elas se imbricam com "a captura" para perpetuar o funcionamento social do regime. É especialmente o caso quando ele observa a importância da "tufta" (a sabotagem das normas, a maquiagem dos resultados, o improviso da produção), a respeito da qual Soljenítsin escreve que, diferentemente das outras três "baleias" que "sustentam o arquipélago", ela é "obra dos indígenas e da própria vida", e conclui que "então o erro seria, ao que parece, confundir o projeto do sistema de coação com seus efeitos em retorno no real"'21.

Enfim, Lefort retorna a um trabalho de Gérard Duchêne, o qual afirma que no âmbito do Plano, a legalidade é a tal ponto incoerente que ela impõe que todos se coloquem fora da lei. Duchêne defende a hipótese de que exista um interesse das autoridades de agir dessa maneira, antes de estimar que na medida em que elas mesmas sofrem os efeitos da degradação da lei, as coisas não podem ser desta forma. Ao invés disso, ele vê na "persistência de uma economia oficial que soa falsa, e que aparentemente não rima com nada", "uma garantia da unidade social, tanto por seu conteúdo (que é o discurso da unidade e da racionalidade), quanto por seu caráter obrigatório e monopolista. Ela é sinal da existência da sociedade soviética" ${ }^{22}$.

Lefort não reflete tanto sobre a função que essas formas de desvio com relação a perpetuação do sistema totalitário poderiam desempenhar. Mais do que isso, ele vê nelas um efeito a mais dessa "conjunção da lei e do poder social, cuja consequência seria de converter objetivamente todo cidadão em culpado potencial". Ele deduz desse fato que "o fenômeno está fora do campo de consciência dos dirigentes do Estado e do partido, e que estes não se dão conta da degradação da lei, nem do fato de que seu próprio poder se encontra minado"23. Esta última conclusão está de acordo com o raciocínio decididamente filosófico de Lefort: se há "funcionalismo", ele só pode ser consubstancial a uma forma do político, a "uma maneira de ser em sociedade". Tentar encontrar suas ligações com um modo efetivo de dominação equivale a ceder a uma "ilusão positivista".

\footnotetext{
${ }^{20}$ LEFORT, C.: Un homme en trop, Seuil, 1986, p. 72.

21 Ibid, p. 94.

22 DUCHÊNE, G.: "L'officiel et le parallèle dans l'économie soviétique", Libre, 7, 1980, p. 151-188.

23 LEFORT, C.: La complication, retour sur le communisme, Fayard, 1999, p. 238.
} 
Em contrapartida, ao longo de seus artigos consagrados aos regimes do Leste e a URSS, Claude Lefort descreveu repetidamente um fenômeno de "putrefação social"24. Mesmo que tal fenômeno só tenha afetado a estabilidade do regime e contribuído para seu colapso a partir da revogação do artigo 6 da constituição soviética (artigo este que dava ao partido único o status de vanguarda). A análise lefortiana mostra claramente que o regime soviético também era um sistema, e que a "putrefação social" não influenciava mais a perpetuação do regime enquanto não se produzisse uma ruptura de sua eficácia simbólica. O fim do partido único é simbólico ao mesmo tempo em que ele constituiu um evento. A putrefação do social é um fenômeno dinâmico inscrito a longo prazo. Toda a questão de uma análise sociológica ou antropológica é então de mostrar como os rearranjos no interior do regime não envolveram a modificação das regras fortes, e no fim das contas produziram efeitos de perpetuação.

\section{A luta: uma forma de vida cubana}

Em Cuba, os jogos de linguagem em torno do verbo lutar consistem um índice que nos permite compreender o descarrilamento do projeto totalitário. O slogan "100 anos de luta" apareceu na repercussão do discurso "Porque en Cuba sólo ha habido una Revolución", proferido por Fidel Castro em 10 de outubro de 1968, um século depois do início da Primeira Guerra de Independência. A referência ao conceito de luta não era anódina: a partir do momento em que os limites da tabula rasa foram admitidos oficialmente, existiu uma afinidade seletiva entre a "marcha revolucionária" (no mínimo aleatória) e o "progresso na direção do comunismo". Atualmente, se reunirmos os fragmentos que reaparecem mais frequentemente no jargão da rua, uma descrição da experiência social se forma da seguinte maneira: "você sufoca, então começa a inventar, e aí você se suja, então tem que se lavar, e pronto, você cai na armadilha do Fidel"25. No quotidiano, a precariedade das condições materiais de vida e os limites impostos pelo Estado sobre as atividades econômicas privadas se unem à impossibilidade de respeitar literalmente a legalidade socialista, e à irracionalidade das normas de trabalho e de produção. Em tal contexto, todos ou quase todos são levados a inventar. $\mathrm{Na}$ escala dos bairros ou das empresas, todos os membros dos comitês de base das organizações de massa são sujos. Os dirigentes foram obrigados a fechar os olhos sobre a generalização das distensões quanto à legalidade socialista: a margem se transformou na norma, e o equilíbrio das transgressões se englobou em um sistema de acordos mutuais. Contudo, os indivíduos permanecem submetidos ao

\footnotetext{
24 LEFORT, C.: Le temps présent, Ecrits 1945-2005, Belin, 2007.

25 "Te sofocas, entonces te pones a inventar, y entonces te marcas, entonces te tienes que limpiar, y ya caes en la mecánica de Fidel".
} 
mesmo tempo à arbitrariedade das leis e à capacidade das autoridades de aplicá-las de forma imprevisível. Em especial, as autoridades recorrem à tática das ondas repressivas direcionadas, já conhecidas pelos cubanos desde o início dos anos sessenta. Quando as circunstâncias aparecem, grupos inteiros podem ser de uma só vez despojados de sua capacidade estratégica. Os lutadores também se dedicam permanentemente a se lavarem. Este imperativo prático consiste antes de tudo em votar e em participar das "atividades" de base da Revolução: pagar sua cota enquanto membro de diversas organizações de massa das quais se participa, ir ocasionalmente a uma "manifestação popular", realizar trabalhos de utilidade coletiva, ou ainda fazer uma doação de sangue.

Mas as autoridades assistem às vezes impotentes a emergência de condutas e discursos potencialmente subversivos, e a linha política é ela própria sujeita a reviravoltas frequentes. Isso faz com que as formas de se lavar se tornem mutáveis e múltiplas. Dessa maneira, os espaços públicos podem ser utilizados como espaços de competição pela conformidade. A vocação oficial dos processos coletivos de autocrítica, decretados ciclicamente pelas mais altas autoridades, é de incutir novamente na dinâmica revolucionária todo o seu vigor. Bastante ativos no terreno do "rastreamento dialético", os altos dirigentes traçam permanentemente novas linhas de divisão. As autoridades culturais, por exemplo, são reduzidas em parte a reagir a cada caso particular, manipulando habilmente a vara e a cenoura. A maioria dos artistas autorizados a assinar contratos fora do país sem que o ministério da cultura se intrometa e sem ter que doar o essencial de seus ganhos ao Estado permanecem prudentemente fora dos temas políticos. Às vezes acontece, é claro, que uma parte desses artistas resmungue ou torne-se mais ousada. Mas as autoridades acabam quase sempre conseguindo transformar a insubordinação em "malentendido". Uma vez que aparecem "ativistas" que se opõem frontalmente às autoridades e que são sancionados com uma privação de liberdade, todos os outros se tornam rebeldes mais tímidos. Músicos e artistas plásticos que assumiam uma posição crítica assistem assim o surgimento das linhas de divisão que os separam de outros indivíduos ou "movimentos" mais independentes ou protestadores. Eles obtêm simultaneamente, e com frequência sem o prever, prebendas às quais eles não tinham acesso até então, como, por exemplo, novas possibilidades de viajar ao exterior para trabalhar. Assumir um papel mais ativo no seio de uma organização controlada pelo estado, assinar uma petição contra "a campanha de difamação de Cuba em Miami”, ou declarar no exterior que eles não se interessam pela política, tudo isso os recoloca "no interior da Revolução".

Os motivos de uns e de outros são diferentes - manter as aparências, não se expor à "lei da periculosidade", limitar os danos no caso de um delito que seria subitamente sancionado, ascender nos escalões da sociedade, entrar e sair livremente da ilha - mas juntas, essas operações perpetuam de uma só vez os símbolos da existência da sociedade revolucionária e o funcionamento social do regime. É a este círculo vicioso que os cubanos 
parecem fazer alusão ao evocar a armadilha de Fidel, que se transformou na de Raul: as estratégias colocadas em prática com o objetivo de se proteger das sanções ao mesmo tempo permitem obter favores e mordiscar margens de ação, sem nunca poder se esquivar das situações de risco e de imprevisibilidade. O enfraquecimento da dimensão simbólica do regime não foi acompanhado de um colapso do sistema de normas que o fazia funcionar. Os esforços de interpretação da experiência revolucionária também não desapareceram totalmente. $\mathrm{Na}$ linguagem do cotidiano, lutar expressa as formas de enfrentar os problemas, mesmo que a validade prática ou moral delas nunca seja estabelecida ${ }^{26}$. E para os dirigentes, a luta se tornou, na falta de objetivos claros, a forma residual do processo revolucionário. A elasticidade do campo lexical da lucha testemunha menos uma subversão ou uma recuperação da linguagem revolucionária e mais a existência de um conhecimento prático comum, de uma interpenetração dos imaginários e de um sentido compartilhado da realidade.

\section{A atualização do modelo socialista}

Imediatamente depois de "assumir suas funções" em fevereiro de 2008, Raúl Castro se contentou em liberar a venda de telefones celulares e computadores, e em permitir aos cubanos o acesso aos hotéis e resorts. Até setembro de 2010, a distribuição aos agricultores de terras cedidas sob condições de uso foi a única "reforma" que pode vir a ter consequências. Naquela época, o governo anunciou a demissão em seis meses de 500000 funcionários públicos "em excesso" (com a previsão de 1,8 milhões até o final de 2014), cerca de 10\% da "massa de trabalhadores". Mas ele acrescenta que, no âmbito de um conjunto de disposições, todos esses indivíduos serão demitidos para que possam ser realocados em uma das 178 atividades "por conta própria" que já são legais ou que foram recentemente autorizadas. Em última análise, essas reformas têm como objetivo limpar as contas do Estado, através da redução dos custos da segurança social e do aumento das receitas fiscais proporcionais ao número de novos "trabalhadores por conta própria".

As atividades privadas legais continuam sendo muito limitadas, e os "profissionais" (os universitários diplomados, e especialmente os do setor médico e de pesquisa) ainda não podem exercê-las. Quanto à concessão de novas licenças, esta é restrita a atividades escolhidas a dedo, das quais umas parecem mais aleatórias que as outras: fornecedor de serviços gastronômicos, locador de quarto, transportador, carpinteiro, chaveiro, barbeiro, por exemplo; mas também vendedor de CD, gestor de viagens, treinador esportivo, maquiador, massagista, empregado doméstico, descascador de frutas, podador de palmeira, reparador de guarda-chuvas e de guarda-sóis, figurante, palhaço, etc.

26 BLOCH, V.: "Le sens de la lutte, Communisme 85/86”, L'Age d'Homme, 2006, p. 125-147. 
Os próprios termos desses decretos e disposições continuam a testemunhar a perversão da lei ${ }^{27}$. Em especial, em virtude de um decreto de agosto de $2008^{28}$, a concessão de uma parcela de terra é condicionada "à observação de uma conduta moral e social de acordo com os princípios éticos da nossa sociedade". A "convenção sobre as relações e obrigações entre o usuário e o Delegado Municipal" é revisada a cada ano. E ela só é renovada se o usuário tiver cumprido suas obrigações, dentre as quais a principal é, por definição, demasiadamente aberta à interpretação, ou pelo menos mais do que outras, sendo "a produção e manutenção sustentável das terras e o aumento da produção". Conduzida pelo próprio Delegado Municipal, tal revisão se revela em última análise como pertencente à competência das autoridades políticas locais. Finalmente, o artigo 28 especifica que pode acontecer que a convenção seja "finalizada" por "motivos de utilidade pública ou de interesse social”.

Da mesma forma, uma Resolução de outubro de 2010 do Ministério do Trabalho e da Segurança Social ${ }^{29}$ estabelece aos "trabalhadores por conta própria" certos "deveres" que têm uma formulação tão pouco normalizada que dá margem a interpretações completamente arbitrárias. Em virtude do artigo 8, os "trabalhadores por conta própria" devem, por exemplo, "mostrar-se responsáveis em relação à qualidade da produção que eles realizam e dos serviços que eles oferecem", ou ainda "manter, nos lugares em que exercem suas atividades, o respeito às normas de decoração pública, da segurança no trabalho, da higiene comunitária e sanitária e da preservação do meio ambiente". Outras regras estabelecidas nos termos do artigo 8 são simplesmente impossíveis de serem cumpridas. Um podador de palmeiras ou um descascador de frutas terá, por exemplo, grande dificuldade de se contentar em "realizar exclusivamente a atividade ou atividades para as quais [ele] recebeu uma autorização". Na medida em que muitos produtos alimentares estão disponíveis apenas no mercado negro, a maioria dos "trabalhadores por conta própria" do setor gastronômico poderão tampouco se limitar a "usar no exercício do seu trabalho matérias-primas, materiais e equipamentos de proveniência legítima".

A lógica das reformas visa recompensar a fidelidade política sem dar espaço a uma divisão de interesses entre o setor público e o setor privado, o qual permanece sujeito à arbitrariedade jurídica e a bruscas mudanças de direção implementadas a partir do cume do poder. Além disso, a normalização incutiu um novo vigor ao movimento produzido pelas lógicas antagônicas do funcionamento social: a impossibilidade de respeitar ao pé da letra a legalidade socialista justifica a intensificação da "luta contra as indisciplinas e contra a corrupção", bem como a mobilização revolucionária contra os "burocratas", considerados

27 Gaceta Oficial del 08/10/2010; Decreto-Ley nº292 del 27/09/2011; Decreto-Ley $n^{\circ} 288$ del 2/11/2011.

28 Decreto-Ley $n^{\circ} 259$ del 10/07/2008; Decreto-Ley $n^{\circ} 282$ del 29/08/2008.

${ }^{29}$ Gaceta Oficial del 08/10/2010. 
responsáveis pelos "bloqueios". Nessa situação, os indivíduos que se beneficiaram das "reformas" arriscam a todo momento se encontrarem desprovidos de sua capacidade estratégica.

\section{Os emigrantes "leais à pátria"}

Se as reformas perpetuam o funcionamento social do regime, elas visam também e apesar de tudo restabelecer uma ordem política sobre uma base social mais larga. Por um lado, a posição econômica dos dirigentes e das empresas gerenciadas pelo exército foram ainda mais reforçadas, a fim de negociar nas melhores condições possíveis no caso de uma transição feita a partir de um pacto se mostrar inevitável. Por outro lado, os cuentapropistas, os cubanos que entram e saem da ilha como querem, assim como os artistas "críticos" que se inseriram no mercado internacional da cultura podem se beneficiar das reformas, contanto que eles apoiem em troca os limites que foram fixados pela elite no poder.

$\mathrm{Na}$ língua castrista, os 900.000 cubanos que partiram em exílio para os Estados Unidos entre 1959 e 1993 eram "traidores" e "apátridas". Em contrapartida, os 600.000 de seus compatriotas que se encontraram com eles desde então são "vítimas da crise econômica" e do "bloqueio americano". Desde a assinatura dos acordos de 1994, os refugiados cubanos devem tocar o solo americano para beneficiar do Cuban Adjustment Act. Promulgada em 1966, esta lei oferece aos cidadãos cubanos que deixaram seu país a oportunidade de se tornarem residentes dos Estados Unidos depois de um ano de presença contínua no território nacional. Do seu lado, o governo cubano relaxou lentamente as condições para a concessão de "autorização para deixar o território" e de "títulos de residência no exterior". Ele também simplificou as "habilitações de passaporte para a entrada no território" obtidas nos consulados de Cuba no exterior. Os emigrantes julgados "leais à pátria" obtêm a "palavra mágica" para retornar a Cuba como bem entendem. Em virtude de uma reforma que entrou em vigor em janeiro de $2013^{30}$ e que exclui os militares, os executivos e "os profissionais de saúde e de educação", os procedimentos impostos para viajar para fora da ilha foram substituídos por um pedido de passaporte. Contudo, a lei prevê que este pode ser recusado por motivos "de interesse público" ou de "segurança e defesa nacionais". Essa reforma fez também passar de onze a vinte e quatro meses a duração máxima de residência legal no exterior para um cidadão cubano. Nesta nova configuração, muitos sonham tornar-se cidadãos com residência dupla. Nos últimos dias de sua presidência, Barack Obama revogou a cláusula "pés secos, pés molhados", mergulhando no desespero milhares de cubanos que, estando em trânsito - às vezes há

${ }^{30}$ Gaceta Oficial del 16/10/2012. 
meses ou até anos no Equador, na Colômbia, na América Central ou no México -, planejavam alcançar a fronteira ao sul dos Estados Unidos.

De muitas maneiras, os migrantes cubanos já não são uma exceção em comparação com os emigrantes do resto do Caribe e da América Latina que se instalaram nos Estados Unidos. Há cerca de vinte anos, as diferenças econômicas entre os dois grupos tendem a desaparecer ${ }^{31}$. Mas acima de tudo, diferente das gerações precedentes de exilados, a maior parte dos "refugiados" dos vinte últimos anos voltam regularmente a Cuba. Estima-se que a quantidade de remessas atinge de dois a quatro bilhões de dólares por ano, o que faz desta a maior fonte de renda para a ilha. A partir dos Estados Unidos, pode-se enviar comida a pessoas que moram em Cuba. Ou ainda adicionar crédito para um telefone celular, mesmo que todas as operadoras pertençam ao Estado. Os emigrantes trazem bens de equipamento, materiais de construção, roupas, cosméticos, etc., e são expostos à arbitrariedade das normas alfandegárias.

Os migrantes que vão e vêm entre a ilha e os Estados Unidos aprenderam acima de tudo a respeitar os limites fixados pela elite no poder. Em troca de uma liberdade relativa de movimento e do direito de gastar seu dinheiro como eles bem entendem quando eles estão em Cuba, eles sabem que devem restringir os motivos de suas visitas às reuniões familiares, ao retorno às origens culturais e às viagens de lazer. Para esses emigrantes leais à pátria, renunciar à reivindicação dos direitos políticos é um custo tão mais aceitável que o essencial é deixar livre uma consumação revanchista, em sinal de triunfo sobre o "sistema".

\section{Conclusão: a ilusão do contágio democrático}

Barack Obama justificou sua decisão de restabelecer as relações diplomáticas com Cuba e de chegar à retirada do embargo comercial alegando que a política que visava isolar a ilha não havia produzido nenhum fruto desde 1961. Tal afirmação é sinal de bom senso, mas a alternativa que ele propõe, "empoderar a sociedade civil", soa mais como um slogan banalizado do que como uma estratégia. A ideia de um contágio democrático de pessoa (americana ou cubana-americana) a pessoa (cubana) sofre da falta de qualquer fundamento. As estadias turísticas em Cuba vêm mais para satisfazer uma sede de exotismo e de sensações fortes do que para dar lugar a cumplicidades militantes. A internet tampouco é uma panaceia: a livre circulação de informação concerne tanto os eventos silenciados pela mídia cubana quanto os resultados dos campeonatos de futebol ou as aventuras das people, sem falar dos fóruns de encontros e sites mais triviais. As ideias de "dar condições" e de "comprometimento" fazem uma abstração completa da realidade da relação que os

31 PORTES, A.: "A Bifurcated Enclave: The Peculiar Evolution of the Cuban Immigrant Population in the Last Decades", Keynote Address, Ninth Conference on Cuban and Cuban-American Studies, Florida International University, May 23, 2013. 
emigrantes "leais à pátria" fixaram progressivamente com o sistema castrista ao longo dos vinte últimos anos. Tal relação contém o indício de uma forma de vida, a luta, a qual arrisca se transformar na matriz das novas relações comerciais que Barack Obama vislumbra caso um dia o embargo seja retirado ou completamente esvaziado de sua substância. O partido único continua a negar o conflito e as divisões sociais, e não pretende renunciar nem à administração do poder através da arbitrariedade jurídica, nem à explicação e transformação do real pela ideologia, nem ao poder de colocar a sociedade em movimento permanente. Não apenas os emigrantes "leais à pátria" e os artistas autorizados a assinar contratos no exterior serviram de terreno de teste ao castrismo de mercado, mas também os dirigentes cubanos aprenderam as lições da abertura aos investimentos estrangeiros. As empresas europeias, canadenses ou latino-americanas que investiram em Cuba nos últimos vinte anos nunca protestaram contra as condições de trabalho de seus empregados, ou contra o fato de que estes recebiam uma parte ínfima de seu salário, que era pago diretamente ao Estado. Barack Obama tomou cuidado também de não aparecer simplesmente como um idealista, e fez apelo aos "interesses americanos": por que deixar o resto do mundo receber a maior fatia do bolo?

Finalmente, a única instituição suscetível de veicular as reivindicações democráticas se situa de agora em diante "no interior da Revolução" - ao lado dos grupos críticos cuja opinião se expressa em vistas de perpetuar "a Revolução", de construir o socialismo e de manter a ordem face às ameaças de desestabilização maquinadas a partir do exterior. Em troca do papel de intermediária que lhe foi provisoriamente reconhecido no diálogo com "a comunidade emigrante" e outros interlocutores estadunidenses, a Igreja Católica acompanha "o processo de adaptação do socialismo". Em contrapartida, ela está autorizada a reforçar seu ativismo social. Por efeito de subtração, os dissidentes e os grupos que se exprimem em nome da "sociedade civil" independente são rejeitados ao lado dos contrarrevolucionários que não têm "nenhum direito" 32 .

\section{MARKET CASTRISM: A LEFORTIAN READING}

Abstract: The article intends to make an analysis of market castrism, which introduced an actualization to the cuban socialist model, through Lefort's perspective of comprehension of the political.

Keywords: Claude Lefort - Cuba - socialism - democracy.

${ }^{32}$ BLOCH, V.: "Reflexões sobre a dissidência cubana", Revista Eletrônica da ANPHLAC, n8, 2009 


\section{Referências bibliográficas}

ARON, R.: Démocratie et totalitarisme, Gallimard, 1965.

ARENDT, H.: Les origines du totalitarisme \& Eichmann à Jérusalem, Quarto Gallimard, 2002.

BLOCH, V.: "Reflexões sobre a dissidência cubana", Revista Eletrônica da ANPHLAC, nº, 2009.

“Le sens de la lutte, Communisme 85/86”, L'Age d’Homme, 2006, p. 125-147.

BROZSAT, M.: Bayern in der NS-Zeit. Herrschaft und Gesellschaft im Konflikt, Band IV. Teil C, De Gruyter Oldenbourg, 1981

CASTORIADIS, C.: L'institution imaginaire de la société, Seuil, 1975.

Sur le Politique de Platon, Seuil, 1999.

DOMÍNGUEZ, J. I.: “Comienza una transición hacia el autoritarismo en Cuba?”, Encuentro de la cultura cubana, 6-7 (otoño-invierno), 1997, pp. 7-23.

DUCHÊNE, G.: “L'officiel et le parallèle dans l'économie soviétique”, Libre, 7, 1980, p. 151-188.

FIGES, O.: The Whisperers: Private Life in Stalin's Russia, Picador, 2008.

FITZPATRICK, S.: Everyday Stalinism. Ordinary Life in Extraordinary Times: Soviet Russia in the 1930s, Oxford University Press, 2000.

FRIEDRICH, C. \& BRZEZINSKI, Z.: Totalitarian Dictatorship and Autocracy, Harvard University Press, 1965.

LEFORT, C.: Le temps présent, Ecrits 1945-2005, Belin, 2007.

Un homme en trop, Seuil, 1986, p. 72.

La complication, retour sur le communisme, Fayard, 1999.

. "Permanence du théologique-politique ?", in: Essais sur le politique, Seuil, pp. 251300. 
LINZ, J. \& STEPAN, A: Problems of Democratic Transition and Consolidation, The Johns Hopkins University Press, 1996.

MONTESQUIEU: De l'Esprit des lois, éditions Garnier Frères, 1961 [1748].

PORTES, A.: "A Bifurcated Enclave: The Peculiar Evolution of the Cuban Immigrant Population in the Last Decades", Keynote Address, Ninth Conference on Cuban and CubanAmerican Studies, Florida International University, May 23, 2013. 